\title{
Total Laparoscopic Gastrocystoplasty: Experimental Technique in a Porcine Model
}

\author{
Frederico R. Romero, Claudemir Trapp, Michael Muntener, Fabio A. Brito, Louis R. \\ Kavoussi, Thomas W. Jarrett
}

The James Buchanan Brady Urological Institute, The Johns Hopkins Medical Institutions (FRR, CT, $M M, F A B)$, Maryland, Baltimore, The Department of Urology, North Shore-LIJ Health System (LRK), Long Island, New York and Department of Urology, The George Washington University Medical Center (TWJ), Washington, DC, USA

\begin{abstract}
Objective: Describe a unique simplified experimental technique for total laparoscopic gastrocystoplasty in a porcine model. Material and methods: We performed laparoscopic gastrocystoplasty on 10 animals. The gastroepiploic arch was identified and carefully mobilized from its origin at the pylorus to the beginning of the previously demarcated gastric wedge. The gastric segment was resected with sharp dissection. Both gastric suturing and gastrovesical anastomosis were performed with absorbable running sutures. The complete procedure and stages of gastric dissection, gastric closure, and gastrovesical anastomosis were separately timed for each laparoscopic gastrocystoplasty. The end-result of the gastric suturing and the bladder augmentation were evaluated by fluoroscopy or endoscopy.

Results: Mean total operative time was 5.2 (range 3.5 - 8) hours: 84.5 (range 62 - 110) minutes for the gastric dissection, 56 (range 28 - 80) minutes for the gastric suturing, and 170.6 (range 70 to 200) minutes for the gastrovesical anastomosis. A cystogram showed a small leakage from the vesical anastomosis in the first two cases. No extravasation from gastric closure was observed in the postoperative gastrogram.

Conclusions: Total laparoscopic gastrocystoplasty is a feasible but complex procedure that currently has limited clinical application. With the increasing use of laparoscopy in reconstructive surgery of the lower urinary tract, gastrocystoplasty may become an attractive option because of its potential advantages over techniques using small and large bowel segments.
\end{abstract}

Key words: laparoscopy; bladder; gastroplasty; experimental; pigs

Int Braz J Urol. 2007; 33: $94-9$

\section{INTRODUCTION}

Introduced by Sinaiko as an experimental study in 1956, (1) gastrocystoplasty was later adapted for clinical practice by Leong and Ong $(2,3)$.

Gastrocystoplasty was initially conceived to avoid complications frequently present when using the small or large bowel segments to augment the bladder, such as excessive mucus production, hyperchloremic metabolic acidosis, and consequent bone rarefaction and growth problems in the pediatric population (1-3).

The emergence of complications caused by gastric secretion, including hematuria-dysuria 
syndrome and hypochloremic metabolic alkalosis, as well as necessity for a large abdominal incision to harvest the gastric wedge and anastomose it to the bladder, have restricted the use of gastrocystoplasty (4-6).

Recently, many laparoscopic studies have been performed, in an attempt to minimize the distress of urinary reconstruction, avoiding large incisions and their destructive psychological and physical consequences (7-11). These reports showed the feasibility of bladder augmentation through laparoscopic approach, improving cosmesis and decreasing postoperative morbidity. The majority of these publications have been done using intestinal segments, (8-10) usually with a hand-assisted method $(10,11)$.

To further increase the therapeutic options and to reduce the morbidity of lower urinary tract reconstructive surgery, we describe a unique simplified experimental technique for total laparoscopic gastrocystoplasty in a porcine model.

\section{MATERIAL AND METHODS}

Ten female Sus-scrofus domesticus piglets, with an average weight of $65 \mathrm{lb}$ were used in this study. The experiment protocol was approved by the Institutional Animal Care and Use Committee. The animals received nothing per mouth for 12 hours before the procedure. Each animal was premedicated with an intramuscular injection of telazol, ketamine, and xylazine (TKX, $1 \mathrm{~mL} / 50 \mathrm{lb}$ ). Once the animals were tranquilized, anesthesia was induced with intravenous thiopental $(10 \mathrm{mg} / \mathrm{lb})$ and maintained with isofluorane inhalation $(1.5 \%-2 \%)$.

The animals were positioned supine. Pneumoperitoneum $(15 \mathrm{~mm} \mathrm{Hg})$ was achieved with a Veress needle at the level of the umbilicus, followed by introduction of three $10 \mathrm{~mm}$ trocars under direct vision: in the midline, four fingerbreadths to the right, and four fingerbreadths to the left, at the level of the umbilicus. When necessary, a fourth 5 $\mathrm{mm}$ trocar was introduced laterally and in line with the other trocars to assist with suction or traction (Figure-1).
The gastroepiploic arch was identified along the greater gastric curvature. The branches of the right gastroepiploic artery to the anterior and posterior wall of the antrum were carefully mobilized, and transected between hemoclips. The use of electrocautery and unnecessary grasping of the vessels was strictly avoided during this dissection, to prevent injury to the pedicle. Dissection was carried from the origin of the right gastroepiploic artery, at the level of the pylorus, to the beginning of the segment of stomach which was gonna be used as a graft. Adequate mobilization is important to allow enough length for the pedicle to reach the bladder without tension.

After the pedicle was adequately freed, a paper ruler was introduced into the abdomen and a segment of 4 to $6 \mathrm{~cm}$ of stomach was identified. The left gastroepiploic artery was transected immediately

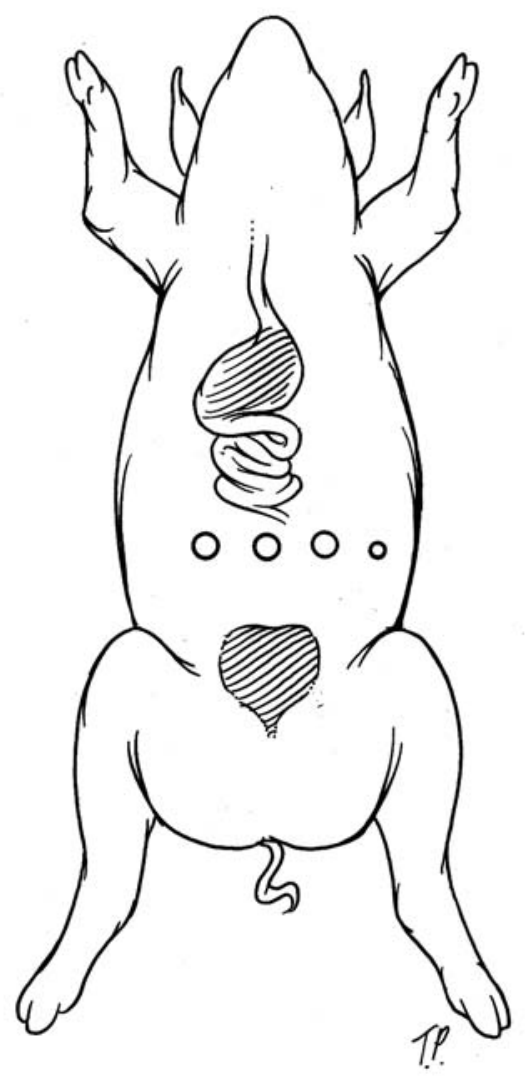

Figure 1 - Animal positioning and trocar placement in relation to the stomach and the bladder. 
after the distal end of the segment with the use of a linear endoscopic stapler or titanium clips. The wedge-shaped segment of stomach was delineated with electrocautery to facilitate the excision of the graft, beginning at the posterior wall, around the pedicle, and at the anterior wall of the stomach. The apex of the wedge was placed $2 \mathrm{~cm}$ away from the lesser gastric curvature to avoid injury to branches of the vagus nerve that control the gastric outlet. Initially, the resection of the gastric wedge was performed by simultaneously cutting the seromuscular and the mucosal layer of the stomach, duplicating the open technique. However, the seromuscular layer retracted behind the mucosa, resulting in redundant mucosal tissue that created difficulties with the visualization of the gastric patch borders during the anastomosis to the bladder. This was solved subsequently by incising the gastric wall in stages. The seromuscular layer was opened first and was easily detached from the underlying mucosa. The mucosal layer was then incised near to the border of the seromuscular patch with the curve of the laparoscopic scissors pointing toward the graft and using slight angulation of the scissors in the same direction, to reduce the amount of mucosal tissue resected.

The native stomach was closed with one layer of running sutures, taking care to invert the gastric mucosa. A stay suture was positioned in the anterior angle of the gastrotomy and pulled outside the abdomen with the assistance of a Carter-Thomason device (Inlet Medical, Eden Prairie, Minnesota, USA), to help in the repair of the stomach and facilitate the placement of the sutures.

The gastric segment was positioned close to the bladder. Care was taken to avoid twisting of the pedicle (Figure-2). The bladder was opened in a sagittal plane in the midline from the bladder neck anteriorly, through the dome, to the trigone posteriorly. Two stay sutures were placed in each side of the bladder to assist in the anastomosis. The first suture was placed in the left lateral aspect of the bladder wall and the right corner of the gastric wedge. With another suture, the right border of the bladder incision was sutured to the left corner of the gastric wedge, and the wedge was approximated to the native bladder. The posterior wall of the anastomosis was performed with absorbable running sutures, with caution to include all the layers of the stomach. After the posterior wall was concluded, the anterior wall of the anastomosis was performed in the same way as with the posterior anastomosis.

At the end of the procedure, a gastrogram was performed with $300 \mathrm{cc}$ of contrast 50\%, to confirm closure of the stomach. A cystogram (300 cc of contrast 50\%) or cystoscopy under intraabdominal visualization was performed to confirm a watertight bladder reconstruction.

The complete procedure and the stages of gastric dissection, gastric closure, and gastrovesical anastomosis were separately timed for each laparoscopic gastrocystoplasty. The end-result of the

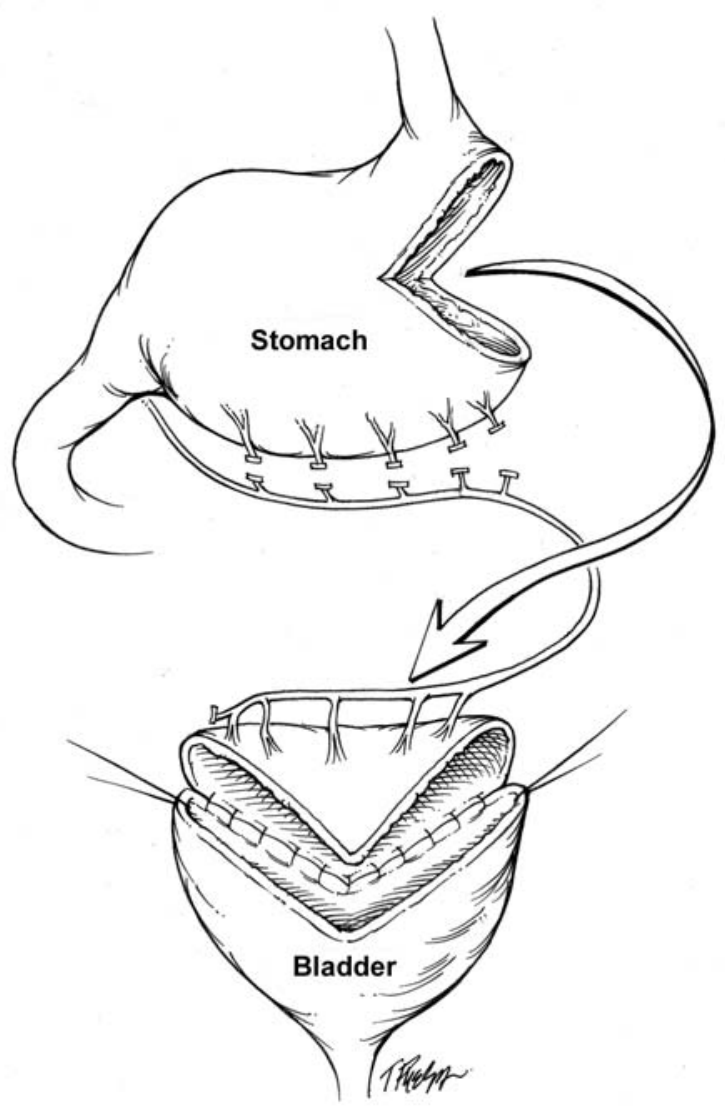

Figure 2 - The wedge-shaped gastric flap is brought with its blood supply close to the bladder, taking care to avoid twisting of the pedicle (note that all clips are facing the left side of the gastric pedicle). 
gastric suturing and the bladder augmentation were evaluated by fluoroscopy or endoscopy, after which the animals were sacrificed. Postmortem laparotomy was performed to inspect the final result of the gastrocystoplasty.

\section{RESULTS}

The mean total operative time was 5.2 hours (range 3.5 to 8 hours). The gastric dissection took an average of 84.5 minutes (range 62 to 110 minutes), the gastric suturing 56 minutes (range 28 to 80 minutes), and the gastrovesical anastomosis $170.6 \mathrm{~min}$ utes (range 70 to 220 minutes). Cystogram showed a small leakage from the gastrovesical anastomosis in the first two cases. No extravasation from the gastric closure was observed in the postoperative gastrogram. Laparotomy confirmed these results, showing a defect in the posterior anastomosis as the cause of the bladder leakage in the first two experiments.

\section{COMMENTS}

Docimo et al. reported the first laparoscopic bladder augmentation in 1995 (7). Since then, the laparoscopic approach has been increasingly used to perform either augmentation or total replacement of the bladder (8-11). The objectives have been to reduce the morbidity of these complex procedures and to expand laparoscopic reconstructive surgery in both pediatric and adult urology (8-13). Most techniques employ the small or large bowel and maintain the same principles of conventional open surgery. Usually, the intestinal segment is detubularized, refashioned, and sutured to the bladder using either intracorporeal or, most frequently, extracorporeal suturing.

In the past decade, many authors restricted the indications of open gastrocystoplasty because of the increasing appearance of hematuria-dysuria $(6,14)$, despite the small number of patients presenting this complication in several series and the good response to clinical management with proton pump inhibitors $(14,15)$. Another complication reported, the hypocloremic metabolic alkalosis (5), is a rarely seen entity that can be prevented by proper electrolyte correction in the management of acute diarrhea. Despite these particular complications, the stomach is a useful alternative in selected patients with a poorly compliant or a high-pressure bladder that need bladder augmentation. Short bowel syndrome, renal insufficiency with metabolic acidosis, and previous pelvic irradiation are clinical situations in which gastrocystoplasty would be the preferred form of bladder augmentation $(2,4,15,16)$. Other situations in which gastrocystoplasty may be used include the necessity for a pouch with less mucous production and in patients with recurrent urinary lithiasis $(3,17)$.

With the increasing use of laparoscopy in reconstructive surgery of the lower urinary tract, gastrocystoplasty may be an attractive option because of its advantages over the techniques using small and large bowel segments. It eliminates the need of detubularization and refashioning of the bowel, reducing the amount of intracorporeal suturing. Also, in contrast to other intestinal segments, the gastric flap is more similar to the bladder wall in thickness, facilitating an even coaptation during the anastomosis.

Pure laparoscopic gastrocystoplasty is a feasible procedure (7). The porcine experimental model duplicates the anatomy of the gastric and urinary tracts in humans relatively well, and it is known to be a good training modality for advanced laparoscopic techniques. Although this was not a survival study, this simplified surgical technique may enable surgeons to practice both dissection and suturing skills required in extirpative and reconstructive laparoscopic surgery. If this were a survival procedure, some important technical aspects should be pointed. Although intracorporeal gastric suturing is a well-established technique for gastric closure and it is specially useful for surgical skills training, laparoscopic stapling of the stomach avoids the risk of peritoneal contamination and allows for a faster gastric wedge resection. The gastric patch pedicle should be retroperitonealized by releasing the right colon medialy and lying the right gastroepiploic pedicle in the retroperitoneum. The augmented bladder should be drained by suprapubic cystostomy, 
and two abdominal drains should also be placed through the ports to drain gastric and bladder sutures.

Regardless of the gastrointestinal segment chosen, several benefits are obtained with the laparoscopic approach. Decreased perioperative morbidity, less need for postoperative analgesics, faster recovery time, and improved cosmetic results are the main advantages favoring laparoscopy over the open techniques $(7,8,13)$. Furthermore, advancements in tissue engineering technology may allow the use of demucosalized gastric segments as a vehicle to transport in vitro expanded urothelial cells during bladder reconstruction $(18,19)$. The ease with which the gastric mucosa can be detached from the seromuscular layer of the stomach may allow gastrocystoplasty to be a handy transport matrix.

The development of the laparoscopic approach and the recent advancements in tissue engineering may allow demucosalized gastrocystoplasty to be applied more extensively in the near future, avoiding the complications inherent to the gastric mucosa.

\section{CONCLUSIONS}

Total laparoscopic gastrocystoplasty is a feasible but complex procedure that currently has limited clinical application. With the increasing use of laparoscopy in reconstructive surgery of the lower urinary tract, gastrocystoplasty may become an attractive option because of its potential advantages over the techniques using bowel segments. Additional survival and clinical studies, specially with the use of the modified demucosalized technique with urothelial cells grafting, are necessary to evaluate the perspectives of laparoscopic gastrocystoplasty in the future.

\section{ACKNOWLEDGEMENTS}

The authors express appreciation to Carolyn Magee and Laurie Pipitone for assistance with animals and procedures, and to Timothy Phelps for the preparation of medical illustrations.

\section{CONFLICT OF INTERERST}

None declared.

\section{REFERENCES}

1. Sinaiko E: Artificial bladder from segment of stomach and study of effect of urine on gastric secretion. Surg Gynecol Obstet. 1956; 102: 433-8.

2. Leong $\mathrm{CH}$, Ong GB: Gastrocystoplasty in dogs. Aust N Z J Surg. 1972; 41: 272-9.

3. Leong $\mathrm{CH}$, Ong GB. Proceedings: gastrocystoplasty. Br J Urol. 1975; 47: 236.

4. Adams MC, Mitchell ME, Rink RC: Gastrocystoplasty: an alternative solution to the problem of urological reconstruction in the severely compromised patient. $\mathbf{J}$ Urol. 1988; 140: 1152-6.

5. Gosalbez R Jr, Woodard JR, Broecker BH, Warshaw B: Metabolic complications of the use of stomach for urinary reconstruction. J Urol. 1993; 150: 710-2.

6. Nguyen DH, Bain MA, Salmonson KL, Ganesan GS, Burns MW, Mitchell ME: The syndrome of dysuria and hematuria in pediatric urinary reconstruction with stomach. J Urol. 1993; 150: 707-9.

7. Docimo SG, Moore RG, Adams J, Kavoussi LR: Laparoscopic bladder augmentation using stomach. Urology. 1995; 46: 565-9.

8. Elliott SP, Meng MV, Anwar HP, Stoller ML: Complete laparoscopic ileal cystoplasty. Urology. 2002; 59: 93943.

9. Gill IS, Rackley RR, Meraney AM, Marcello PW, Sung GT: Laparoscopic enterocystoplasty. Urology. 2000; 55: $178-81$.

10. Hedican SP, Schulam PG, Docimo SG: Laparoscopic assisted reconstructive surgery. J Urol. 1999; 161: 26770.

11. Specht M, Pareek G, Lin DD, Bleustein C, Fahey TJ 3rd, Felsen D, et al.: Hand-assisted laparoscopic autoaugmentation gastrocystoplasty. Surg Endosc. 2002; 16: 1538-41.

12. Anderson KR, Clayman RV: Laparoscopic lower urinary tract reconstruction. World J Urol. 2000; 18: 349-54.

13. Chung SY, Meldrum K, Docimo SG: Laparoscopic assisted reconstructive surgery: a 7-year experience. J Urol. 2004; 171: 372-5.

14. Chadwick Plaire J, Snodgrass WT, Grady RW, Mitchell ME: Long-term follow-up of the hematuria-dysuria syndrome. J Urol. 2000; 164: 921-3. 
15. DeFoor W, Minevich E, Reeves D, Tackett L, Wacksman J, Sheldon C: Gastrocystoplasty: long-term followup. J Urol. 2003; 170: 1647-9.

16. Gearhart JP, Peppas DS, Jeffs RD: The application of continent urinary stomas to bladder augmentation or replacement in the failed exstrophy reconstruction. $\mathrm{Br}$ J Urol. 1995; 75: 87-90.

17. Carr MC, Mitchell ME: Gastrocystoplasty. ScientificWorldJournal. 2004; 4 Suppl 1: 48-55.
18. Shiroyanagi Y, Yamato M, Yamazaki Y, Toma H, Okano T: Urothelium regeneration using viable cultured urothelial cell sheets grafted on demucosalized gastric flaps. BJU Int. 2004; 93: 1069-75.

19. Atala A, Koh C: Applications of tissue engineering in the genitourinary tract. Expert Rev Med Devices. 2005; 2: 119-26.

\author{
Correspondence address: \\ Dr. Frederico Ramalho Romero \\ The Johns Hopkins Medical Institutions \\ The James Buchanan Brady Urological Institute \\ 600 North Wolfe Street, Marburg 1 \\ Baltimore, Maryland, 21287, USA \\ Fax: + 1410 502-7711 \\ E-mail: frederico.romero@gmail.com
}

\section{EDITORIAL COMMENT}

Augmentation cystoplasty is needed to treat some congenital pediatric and adult urological diseases. Although several substitutes have been employed, the vascularized intestinal segments are still the most commonly used tissue for this reconstruction, despite the described long-term complications. The minimally invasive approach for bladder augmentation has been described and may decrease the perioperative morbidity of this procedure (1).

The authors described a minimally invasive technique for gastrocystoplasty in a non-survival porcine model and should be congratulate for their initiative. Despite the authors' large experience in advanced laparoscopic cases, the mean operative time extended $5 \mathrm{~h}$, most due to the gastrovesical anastomosis $(3 \mathrm{~h})$, with posterior wall leakage occurring in the initial 2 cases of this series. One alternative to this problem would be a laparoscopic-assisted technique, employing the laparoscopic access to dissect and isolate an adequate gastric segment, performing the anastomosis through a small abdominal incision, in the same fashion as the reconstructive part of current technique of laparoscopic radical cystectomy (2).

\section{REFERENCES}

1. Gurocak S, De Gier RP, Feitz W: Bladder augmentation without integration of intact bowel segments: critical review and future perspectives. J Urol. 2007; 177: 839-44.

2. Haber GP, Campbell SC, Colombo Jr JR, Fergany A, Gill IS: Perioperative outcomes with laparoscopic radical cystectomy: "pure laparoscopic" and "laparoscopicassisted" approaches. Urology. 2007 (submitted).

Dr. Jose R. Colombo Jr. Section of Laparoscopic and Robotic Surgery Glickman Urological Institute, Cleveland Clinic Cleveland, Ohio, USA E-mail: columbj@ccf.org 